\title{
What it Means to be a Scientist
}

\author{
J. M. Johnston \\ Auburn University
}

Sidman's Tactics of Scientific Research (1960) defines the notion of a classic text: It says things of enduring importance that no other work-even those that may in some ways improve on it-treats in as clear and persuasive a manner. It thus joins Bernard's An Introduction to the Study of Experimental Medicine (1865/ 1957) as a methodological treatise that changed the way scientists approached their work. Although Tactics pretends to do no more than describe how to evaluate experimental data in psychology, it formalized a set of experimental practices that had been quietly evolving for many years (Skinner had only teasingly suggested them in his 1956 paper titled, "A Case History in Scientific Method").

Part of the book's importance lies in its depth. Although it is about how to study behavior, a barely implicit subtheme is about the nature of behavior as a scientific subject matter. At still another level, the book is about scientific behavior and the behavioral nature of the process of scientific discovery. In pursuing these themes, Sidman strips away tradition and reveals as never before the essence of scientific method-a set of decidedly informal rules describing interactions among the behavior of the individual researcher and the subject matter (the behavior of the subject). These practices have evolved because they have the effect of maximizing the control of the researcher's behavior by the other two variables.

Given the volume's subtitled agenda of evaluating experimental data, its most pervasive emphasis is on the treatment and use of variability. Here, it offers a dramatically different alternative to the dominant traditions in psychology. Instead of approaching variability for its mathematical convenience in maintaining the logical fiction of deductive validity, Sidman describes a pragmatic way of using behavioral variability to guide the researcher's decisions and interpretations both during and after the experiment. In effect, the researcher speaks to Nature by arranging the conditions of the experiment and listens to Nature's reply by accurately and sensitively measuring and examining the behavior of individual subjects. In this metaphor, behavioral variability is the language by which Nature speaks to the researcher.

Sidman describes the resulting approach to experimental comparisons in intimate detail. Tactics ignores the Fisherian tradition of experimental design in favor of an adjustable and sometimes subtle interplay of changing experimental conditions tenaciously focused on revealing controlling variables -a strategic goal in stark contrast with the dominant practice in psychology of merely looking for a difference between a preordained set of experimental and control conditions. And, unlike some of today's authors, he avoids codifying this approach to creating experimental comparisons with artificial distinctions among "types" of designs that would discourage an understanding of its flexibility.

In spite of Sidman's care, misunderstandings of the use of steady states have for some (presumably those who have not studied Tactics) gradually warped this approach to experimentation out of recognition. For instance, an understanding of the uses of steady state behavior lies at the heart of within subject experimental inference and is a prerequisite to sound behavioral research. The process of either waiting for or actively seeking stable responding is central to the analytical style that characterizes Tactics, and Sidman thoroughly details their educational functions for the researcher. His interest in steady states derives at least as much from what their discovery can tell the researcher about behavior and its sources of control as from their role of facilitating comparisons between conditions. 
Many, however, especially those interested in applied questions, apparently lack the recommended analytic curiosity and thus limit their interest in steady states to the simple function of summarizing the effects of the conditions to be compared. For them, stability often seems to be a goal for its own sake, rather than for what it can teach the researcher about controlling influences. Too often, the search for steady states as a kind of gatekeeper for phase change decisions seems to turn behavioral variability into the researcher's enemy. Instead of being an opportunity to listen to Nature answer the researcher's questions, variability becomes an embarrassment to be avoided, if not by controlling extraneous variables, then by more convenient graphic legerdemain. This drive for defensible conclusions, even at the expense of useful generality gained by identifying controlling variables, often certifies the experimental effort as an advocacy of prior convictions, so often encouraged by the contingencies of the marketplace.

Although Sidman is explicit in his treatment of steady state issues, his advice concerning the seminal topic of experimental questions must be sought in the context of other issues. This priority may be excused, of course, because it precedes the acknowledged domain of the book. Nevertheless, the lack of a thorough discussion of experimental questions is sometimes awkward because many pages of Tactics are devoted to subsidiary discussion of the researcher's curiosities. One often wishes that this opportunity to contrast the scientific interests of the emerging field of behavior analysis with those of other areas of psychology had been more explicitly taken.

The generic experimental question offered by Skinner in The Behavior of Organisms (1938) asked, "What are the relations between the independent and dependent variables?" This takes the corollary form, "What are the sources of control over responding?" It is a broadly curious and open-ended form of query, clearly aimed not only at Truth as the researcher can find it but at Nature's, rather than the researcher's, Truth. In contrast, the modal form of psychology's experimental question is "Is there a difference (between experimental and control conditions)?" This bifurcation of scientific curiosity into the rules of the Twenty Questions Game (all questions must be answered with either yes or no) is not only staggeringly inefficient, it misses the point of the scientific questto understand the nature of the difference. Furthermore, in the hypotheticodeductive context of maintaining a pretence of deductive validity, this interrogative form almost requires advocacy. These fundamental differences in experimental interests remain as important now as three decades ago (Johnston \& Pennypacker, 1986a).

The most painful omission of Tactics - a treatment of behavioral measurement comparable to its consideration of behavioral analysis - is also excusable, both because of the book's scope (Sidman's focus was on evaluating data, not on generating it) and its historical context. Sidman wrote for his peers in the animal laboratory. There was relatively little laboratory research with human subjects in 1960 and virtually no applied behavior analysis. In the operant laboratory, methodological questions about measurement that were not accommodated by accepted practice were few. Satisfactory response classes were usually created by experimental contingencies, and relevant dimensional quantities were observed and recorded by electromechanical equipment. Under these conditions, accuracy of measurement was not usually an important issue.

Today, an increasing proportion of basic operant research uses human subjects (Buskist \& Miller, 1982), and the applied literature is vast, if defining behavioral criteria are not too stringent. The variety of measurement challenges represented by these changes has raised an array of issues unanticipated by Tactics. For example, the convenience of functional response class definitions in the animal laboratory contrasts sharply with definitional dilemmas in applied settings where response classes are typically assigned by the requirements of applied concerns. 
Furthermore, the nature of these response classes and the variety of treatment conditions and controlling variables urge a careful review of dimensional alternatives. Early observational practices in applied settings reflected the default tradition in psychology of human observers watching subjects, thereby encouraging such practices as discontinuous and incomplete observation, which raise serious questions about the meaningfulness and quality of data (Johnston \& Pennypacker, 1986b).

There are still other topics that Tactics slights. For instance, given its agenda, it may be understandable that there is no organized discussion of the quantitative treatment of experimental data. Under the conditions described by Sidman, there is little need for descriptive statistical machinations and no need at all for inferential statistical games. However, the range of behavioral research today exceeds that of the 1950s (although one may sometimes wish that it didn't), and there is unquestionably a place for appropriate quantitative procedures in the study of behavior as an aid to descriptive (though not necessarily inferential) precision.

It is the changes in the field of behavior analysis over the past thirty years, especially its dominant applied focus, that have probably-and most unfortunately-reduced the demand for Tactics. Other works have respectfully stood on Tactics' shoulders to serve this need. Although Tactics is now back in print, there remains the difficult challenge of how to create a demand for it and its legitimate progeny. There is an abundant literature complaining about the quality of methodological training and practice in the field (e.g., Fuqua \& Bachman, 1986). There is no clear evidence that there is any widespread methodological "consciousness raising" underway in the field, however, nor is it clear how that might be accomplished.
Perhaps we should start by worrying about why we are doing research. Tactics is written for scientists, for those who are genuinely interested in learning new things about behavior (whether basic or applied), whatever it takes. Too much of our literature suggests that we are often more interested in showing something that we already "know." When this is the case, the searching, analytical research style described by Sidman is too easily compromised. Only when we do research because we really are trying to learn something, as opposed to all of the other reasons that we do research, will we worry about the effectiveness of our research methods. Tactics of Scientific Research tells us what it means to be a scientist.

\section{REFERENCES}

Bernard, C. (1957). An introduction to the study of experimental medicine (H. C. Greene, Trans.). New York: Dover Books. (Original work published 1865)

Buskist, W. F., \& Miller, H. L. (1982). The study of human operant behavior, 1958-1981: A topical bibilography. The Psychological Record, 32, 249-268.

Fuqua, R. W., \& Bachman, J. (1986). Some factors limiting the applicability of applied behavioral research: Descriptive information in $J A B A$ articles. In A. Poling \& R. Fuqua (Eds.), Research methods in applied behavior analysis (pp. 85-98). New York: Plenum.

Johnston, J. M., \& Pennypacker, H. S. (1986a). The nature and functions of experimental questions. In A. Poling, W. Fuqua, \& R. Ulrich (Eds.), Research methods in applied behavioral analysis: Issues and advances (pp. 29-54). New York: Plenum Press.

Johnston, J. M., \& Pennypacker, H. S. (1986b). Pure and quasi behavioral research. In A. Poling, W. Fuqua, \& R. Ulrich (Eds.), Research methods in applied behavior analysis: Issues and advances (pp. 55-83). New York: Plenum Press.

Sidman, M. (1960). Tactics of scientific research: Evaluating experimental data in psychology. New York: Basic Books.

Skinner, B. F. (1938). The behavior of organisms. New York: Appleton-Century-Crofts.

Skinner, B. F. (1956). A case history of scientific method. American Psychologist, 11, 221-233. 